\title{
Effect of Early Nursing Preparation on Anxiety Among Patients Undergoing Cardiac Catheterization
}

\author{
Samira E. Aboalizm, Nahid F. El Gahsh, Samah E. Masry \\ Department of Medical Surgical Nursing, Faculty of Nursing, Menoufia University, Shebin El-Kom, Egypt \\ Email address: \\ Samiraaboalizm@yahoo.com (S. E. Aboalizm), Fonadnahid@yahoo.com (N. F. E. Gahsh), Drsamahmasry@gmail.com (S. E. Masry) \\ To cite this article: \\ Samira E. Aboalizm, Nahid F. El Gahsh, Samah E. Masry. Effect of Early Nursing Preparation on Anxiety Among Patients Undergoing \\ Cardiac Catheterization. American Journal of Nursing Science. Vol. 5, No. 5, 2016, pp. 222-231. doi: 10.11648/j.ajns.20160505.17
}

Received: October 1, 2016; Accepted: October 12, 2016; Published: October 31, 2016

\begin{abstract}
When patients are hospitalized for diagnostic methods, including cardiac catheterization, the anxiety increases. Therefore, treating these reactions can speed up recovery and decrease of anxiety that causes cardiac complication. Study evaluates the effect of early nursing preparation on anxiety among patients undergoing cardiac catheterization. A quasi experimental research design was utilized. The study was conducted at the Cardiac Catheterization Unit of Menoufia University Hospital, Menoufia Governorate, Shebien El-Kom, Egypt. Subjects: A purposive sample of 100 adult patients of both sexes who were admitted to the cardiac catheterization unit. Tools: two tools were utilized. Tool I: cardiac catheterization patients needs assessment: structured interviewing scheduled questionnaire, consisted of the following: Part 1: Sociodemographic and clinical data. Part II: Cardiac Catheterization Knowledge Assessment Sheet. Tool II: Hamilton anxiety rating scale (HAM-A). Results: the study group had better knowledge than control group, there were statistical significant differences were existed between study and control group regarding the anxiety level at day and post procedure at $\mathrm{P}$ values $=$ 0.0001 . There were highly statistically significant difference and correlation existed between anxiety and age, gender and level of education at $\mathrm{p}$ value $=0.0001$. There was a significant correlation between knowledge and anxiety scores at $\mathrm{P}$ value $=0.004$. Conclusion: it can be concluded that, the early preparation and gave patients' information before cardiac catheterization improve patients' knowledge and reduced anxiety.
\end{abstract}

Keywords: Nursing Preparation, Anxiety, Cardiac Catheterization

\section{Introduction}

Coronary artery disease is one of the most common reasons of death all over the world and coronary angiography is used broadly in the evaluation and treatment of this disorder [1]. The World Health Organization has estimated that coronary heart disease currently contributes to 7.1 million deaths yearly on a global basis and will be expected to increase to 11.1 million by the year 2020. Moreover the incidence of death from heart disease in the Eastern Mediterranean region ranges from 25 to $45 \%$. Although many non invasive diagnostic techniques have been commonly used for diagnosis and treatment of heart disease, cardiac catheterization still remains the most definitive procedure and is the golden standard for the investigation of many forms of coronary and structural heart disease [2].

Coronary angiography is a standard method used for the anatomic evaluation of coronary artery disease (CAD) and making decisions about treatment [3, 4]. This procedure is used for diagnostic assessment to confirm or determine the extent and severity of the cardiopathy Cardiac catheterization is generally an elective procedure in which a symptomatic patient with heart disease follows a protocol that requires admission to hospital [5].

The patient may be instructed to fast for 3 to 8 hours before the procedure and withhold or decrease the dosages of scheduled medications (including insulin, antihypertensive drugs, and diuretics). The physician may prescribe pretreatment prophylaxis for the patient with a history of contrast media allergy. Establish two peripheral venous access sites and infuse intravenous fluids as ordered to prevent dehydration. Obtain specimens for lab tests (complete blood cell count, electrolytes, blood urea nitrogen, creatinine, coagulation studies, cardiac biomarkers, and 
urinalysis). Also obtain a chest X-ray and an ECG. The femoral and brachial arteries are common catheter insertion sites, although the radial artery also is an option. Assess and mark pulses on the extremity that will be used. The patients may wear his dentures and eyeglasses during the test. Administer analgesics and sedatives as directed [6].

Anxiety before angiography show that more than $82 \%$ of patients who underwent coronary artery angiography. The incidence rate of anxiety in coronary artery patients before angiography is significantly higher than those without this disease. The relationship between anxiety and cardiovascular system (CVS) is known since the first studies on individuals so called irritable cardiac diseases. Tachycardia and palpitations as a result of severe fear and anxiety related issues, has become a focus of interest in studies that examine the activity of CVS [6].

Waiting for the procedure can be a major source of stress and anxiety. The most important reasons for these feelings are directly related to the invasive nature of the procedure and to uncertainties related to diagnosis [5].In addition to other factors as hospitalization, waiting for CA, fear of complications, lack of information about the process of the $\mathrm{CA}$, care before and after the surgery, and fear of the angiography unit $[7,8]$.

Stress and anxiety influence physiological responses, such as respiratory rate, heart rate, blood pressure, myocardial oxygen consumption, and plasma concentrations of epinephrine and norepinephrine. Increasing the vascular permeability leads to tissue injury and platelet aggregation $[9,10]$.These physiological responses put the patient at risk for dysrhythmia, coronary artery spasm, and rupture [11]. Moreover, because an anxious patient is less likely to collaborate with health care providers, technical problems might occur during the procedure [10]. Some patients may also refuse the CA because of their fear and anxiety. Therefore, it is crucial for nurses to assess and alleviate patients' anxiety before the procedure $[9,12,13]$.

Heart diseases are highly associated with anxiety, which is defined as a state of emotional disturbances that characterized by apprehension, fear and worriness. In cardiac patients, anxiety is a leading cause for increasing heart rate and blood pressure and also the risk of cardiac dysrhythmias [14]. Moreover, it can affect patients' work, decrease their quality of life and increase the risk of death. Therefore, treating these reactions can speed up recovery and increase

The high prevalence of anxiety can delay recovery from cardiac diseases. The adverse physiological and psychological responses to anxiety may also reduce the patients' collaboration with the healthcare team and increase the need for sedative drugs [15]. Therefore, it is necessary to assess the anxiety of patients and their ability to adjust to it before heart catheterization in order to decrease their anxiety and prevent its complication [16].

Patient preparation and instructions given to the patients about the procedure before the surgery can decrease their anxiety and increase the patient's tolerability to postoperative pain. Moreover it can affect positively the sensation of well being and quality of life $[17,18]$. conversely, some patients waiting for CA were not adequately prepared and had not received the necessary information [19], as a result a large number of them were still anxious and worried [20]. Up to now, several studies reported that before the cardiac catheterization procedure the patient's anxiety level were increased with approximating the time scheduled for CA [20, $21,22]$. So nurses have an important role and resposbility to deliver a better care, thus diminishing the stressing factors to reduce patients' anxiety. So the aim of the study was to evaluate the effect of early nursing preparation on anxiety level among patient undergoing cardiac catheterization.

\section{Significance of the Study}

Nowadays, cardiac disease has emerged as the leading cause of death worldwide, particularly in developed countries. The rate of cardiac disease is highest in developed countries [23]. According to World Health Organization, about 18 million deaths occurred due to cardiovascular diseases and this value has been estimated to reach 23 million by 2030 [2]. A cardiac catheterization is perhaps one of the most diagnostic and intervention tools available to the cardiologist today while many of these diagnostic and treatment procedures have become retained for most cardiac nurses in it is a native and an alien procedure for the patient. So cardiac catheterization and coronary intervention (angioplasty) are two wonders of medical technology, which have improved the lives of millions of patients. The nurse helps the patient undergo a cardiac catheterization or interventional procedures do not be intimidated or frightened by these procedures. They are safely and comfortably performed in thousands of hospitals on a daily basis. So most patients waiting for cardiac catheterization lacked adequate information about the procedure and this made them anxious and worried. So the aim of the current study was to evaluate the effect of early nursing preparation on anxiety among patients undergoing cardiac catheterization.

\section{Subjects and Methods}

\subsection{Aim of the Study}

The aim of the study evaluates the effect of early nursing preparation on anxiety among patients undergoing cardiac catheterization.

\subsection{Research Hypotheses}

a. The study group subjects who exposed to the early preparation have more knowledge than control group subjects.

b. The study group subjects who exposed to the early preparation had less anxiety than control group subjects.

\subsection{Research Design}

A quasi experimental research design was utilized to achieve the aim of this study. 


\subsection{Setting}

The present study was conducted at the Cardiac Catheterization Unit of Menoufia University Hospital, Menoufia Governorate, Shebin El-Kom, Egypt.

\subsection{Subjects}

A purposive sample of 100 adult patients of both sexes who were admitted to the cardiac catheterization unit and scheduled for cardiac catheterization procedure were enrolled in this study. They were divided alternatively into two equal groups. 50 patients in each group. They were selected based on the following power analysis:

\subsubsection{Power Analysis: For Sample Size}

The sample sizing assumes that the expected effect size is 6 and the standard deviation of outcome variable is 10 . To achieve $80 \%$ power to detect this difference with a significance level of 0.05 by the equation: $n=\left[\left(Z_{\alpha / 2}+Z_{\beta}\right)^{2} \times\right.$ $\left.\left\{2\left(o^{\prime}\right)^{2}\right\}\right] /(\mu 1-\mu 2)^{2}$ it is estimated that 44 subjects per group would be required. With a withdrawal/non-evaluable subject rate of $10 \%$ a total of 48 per group subjects will be recruited leading to a total required sample size of 96 subjects.

\subsubsection{Inclusion Criteria: Subjects Were Eligible for the Study If They Had the Following Criteria \\ - Adult and conscious patient. \\ - Both sexes. \\ - Age from 18- 60 years \\ - Patients undergoing procedures for the first time.}

\subsubsection{Exclusion Criteria}

- Free from any psychiatric diseases.

- Free from any complication of heart disease that affect on the psychological state of the patient.

- Previous cardiac catheterization.

\subsection{Tools}

Two tools were utilized by the researchers to collect the necessary data. These tools were as following:

\subsubsection{Tool I: Cardiac Catheterization Patients Needs Assessment: Structured Interviewing Scheduled Questionnaire}

This tool was developed by the researchers based on the review of the relevant literature. It was used to determine the needed care for cardiac catheterization patients. The tool consisted of the following 2 parts:

- Part 1: Sociodemographic and clinical data: It was comprised of items related to patients' age, sex, marital status, educational level, occupation, medical diagnosis, and history of associated disease.

- Part II: Cardiac Catheterization Knowledge Assessment Sheet. it composed of 15 questions. It was concerned with items in order to assess patient's cardiac catheterization related knowledge that includes items such as definition of catheterization, causes, sites of catheter entery, number's fasting hours before the procedure, medication, investigation before the procedure, type of anesthesia and time of the procedure, position after the procedure, movement after the procedure, frequency of measuring vital signs, nutrition, methods of urination, post procedure complication and management of the complications.

Scoring system:- Each question has three response categories and for data analysis the respondents answer as following:-

- Correct and complete answer was given a score of three.

- Correct and incomplete answer (partially correct answer) was given a score of two.

- Incorrect answer was given a score of 1 .

The patient's responses were calculated and recorded, then the total score of the patient's knowledge ranged from 15 as a minimum score of 45 as a maximum score and was categorized into: A score of $15<23(<50 \%)$ denoted poor or unsatisfactory results while a score of $23<34$ indicated fair results and a score between 34 and 45 illustrated good or satisfactory results.

\subsubsection{Tool II: Hamilton Anxiety Rating Scale (HAM-A)}

It was developed by Hamilton, (1959) [24]. It was used by the researchers to assess the patient's anxiety state. It consisted of 14 items for evaluation about the psychological and physiological response for anxiety.

Scoring system: Each item was given a score of zero if the answer is not present, one if mild anxiety, two if moderate anxiety, three if severe anxiety, and four if very severe anxiety, then all scores were summed. The possible score ranged from zero to fifty six and the patients were categorized into five groups based on their scores:

A score of 0 means no anxiety,

A score less than 17 indicates mild anxiety,

18-24 means moderate anxiety,

25- 30 means severe anxiety,

While the score more than 30 indicates a very severe anxiety.

\subsection{Method}

\subsubsection{Administrative and Ethical Consideration}

An official letter from faculty of nursing was delivered to responsible authorities of the hospital and approval was obtained to conduct this study after explanation of the purpose of the study.

\subsubsection{Consent}

a formal consent was obtained from patients to participate in the study. The researchers initially introduced themselves to all potential subjects, then explaining the aim of the study and they were assured that all collected data would be absolutely confidential and only will be used for the study' aim. The researchers emphasized that participation in the study is entirely voluntary and anonymity of the patients were assured through coding data. Subjects were also informed that refusal to participate in the study would not 
affect their care. The and they were assured that the collected data were absolutely confidential.

\subsubsection{Tools Development}

the first tool was developed by the researchers after extensive review of the relevant literature and the second tool was developed by (Hamilton, 1959) [24]. Tool 1 was tested for content validity by two experts in the field of nursing specialty and three experts in the field of medical specialty. Modifications were done to ascertain relevance and completeness.

\subsubsection{Reliability of the Tools}

All tools were tested; by intra class correlation coefficient: was used. It was 1.8 for tool I and 4.2 for tool II.

\subsubsection{Pilot Study}

A pilot study was conducted prior to data collection on 10 patients $(10 \%)$ to test all tools for clarity, objectivity, relevance, feasibility and the applicability of the tools. Also, it was conducted to identify any problem associated with administering the tools and measure the time needed for data collection then the necessary modifications were carried out accordingly. Data included in the pilot study was excluded from the current study

\subsubsection{Data Collection}

It was extended from December 2015 to march 2016. The data were collected from both groups, one week before the procedure, on the day of the procedure and post procedure, the researcher assessed knowledge and anxiety level for both groups. Data collected from the control group firstly to prevent contamination of the study data. Participants of both groups were interviewed pre intervention using the tool I to identify patients as assessment needs during pre and post catheterization.

\subsubsection{Implementation Phase}

- After assessment, participants constituted the control group received only routine hospital care. While participants of the study group received the nursing intervention by the researchers in addition to the routine hospital care. (First session).

- The researchers gave knowledge and teaching about pre, post cardiac catheterization through reading the pamphlet (brochure information). The researcher provides each participant of the study group with a written pamphlet and explanation about procedure, cardiac catheterization purpose, patient preparation and position after the procedure, a sensation that might be experienced during the procedure as hot flushing sensation during injection of the dye, as well palpitation or a desire to cough or to urinate.

- Second session on the day of the procedure (before 30 minutes of the procedure) the researchers assess knowledge and anxiety level for both study and control groups.

- Third session done at post cardiac catheterization to evaluate the care and assess the anxiety level among both study and control groups.

\subsubsection{Evaluation Phase}

Participants of both groups were assessed before the procedure on hospital admission and at the day of catheterization each participant in both groups were assessed to identify their problems, knowledge and anxiety level before the procedure and post intervention using tool I and tool II.

\section{Results}

Table (1) Revealed that the mean age of the studied group subjects were $(56.4 \pm 6.59$ and $55.1 \pm 6.59)$ respectively. The study group was equal male and female (50.0\%) However the majority of control group (60\%) were female. The majority of the study and control groups were married and lived in rural areas while $(38 \%$ and $30 \%)$ respectively have primary education. $(38 \%, 42 \%)$ respectively, were housewives, the most of both studied groups were not smoking. Approximately half of study and control groups have hypertension. No statistical significant differences were found between study and control groups regarding socio demographic characteristics.

Table (2):- Showed that no statistical significant differences were existed between study and control groups regarding knowledge of preparation for the procedure at pre intervention period.

Table (3):- Illustrated that no statistical significant differences were found between study and control groups regarding post procedural Knowledge at pre intervention period. Total knowledge scores for study and control groups $(21.90 \pm 4.08$ and $21.80 \pm 4.67)$ respectively.

Figure (1):- Illustrated that about half of the study and control group $(52 \%$ and $\% 50 \%)$ respectively had poor knowledge scores at pre intervention.

Table (4):- Showed that statistical significant differences were existed between study and control groups regarding knowledge of preparation for the procedure at post intervention period at $\mathrm{P}$ values $=0.0001$.

Table (5):- Showed that statistical significant differences were found between study and control groups regarding post procedural knowledge at post intervention $\mathrm{P}$ values $=0.0001$, toal scores knowledge among study $(31.88 \pm 6.43)$ higher than control group (21.50 \pm 4.64$)$.

Figure (2):- Illustrated that about (44\% and 50\%) respectively, of the study group had good and fair knowledge. However, almost half (48\%) of the control group had poor knowledge.

Table (6):- Showed that no statistical significant differences were found between study and control group regarding anxiety level pre procedure at $\mathrm{p}$ values $=0.324$. However, there were statistical significant differences were existed between study and control group regarding the anxiety level at day and post procedure at $\mathrm{P}$ values $=0.0001$.

Table (7):- Showed that total anxiety score among the studied subjects in relation to socio-demographic data. There 
were highly statistically significant difference and correlation existed between anxiety and age, gender and level of education at $\mathrm{p}$ value $=0.0001$.

Table (8):- Illustrated that there was a significant correlation between knowledge and anxiety scores at $\mathrm{P}$ value $=0.004$.

Table 1. Socio demographic characteristics and medical history of studying $\operatorname{group}(n=100)$.

\begin{tabular}{|c|c|c|c|c|c|}
\hline \multirow{2}{*}{$\begin{array}{l}\text { Socio-demographic } \\
\text { characteristics }\end{array}$} & \multicolumn{2}{|c|}{ Study $(n=50)$} & \multicolumn{2}{|c|}{ Control $(n=50)$} & \multirow{2}{*}{$\begin{array}{l}\chi^{2} \\
\text { p value }\end{array}$} \\
\hline & No & $\%$ & No. & $\%$ & \\
\hline \multirow{2}{*}{ Age / years $(\overline{\mathbf{X}} \pm \mathrm{SD})$} & \multirow{2}{*}{\multicolumn{2}{|c|}{$56.4 \pm 6.59$}} & \multirow{2}{*}{\multicolumn{2}{|c|}{$55.1 \pm 6.59$}} & $0.986^{*}$ \\
\hline & & & & & 0.327 \\
\hline \multicolumn{6}{|l|}{ Gender } \\
\hline - Male & 25 & 50 & 20 & 40 & 1.010 \\
\hline - Female & 25 & 50 & 30 & 60 & 0.315 \\
\hline \multicolumn{6}{|l|}{ Marital state: } \\
\hline - Married & 48 & 96 & 49 & 98 & 3.010 \\
\hline - Widow & 0 & 0 & 1 & 2 & 0.222 \\
\hline - Divorced & 2 & 4 & 0 & 0 & \\
\hline \multicolumn{6}{|l|}{ Level of education: } \\
\hline - Illiterate & 12 & 24 & 14 & 28 & 1.075 \\
\hline - Primary education & 19 & 38 & 15 & 30 & 0.783 \\
\hline - Secondary education & 10 & 20 & 13 & 26 & \\
\hline - University & 9 & 18 & 8 & 16 & \\
\hline \multicolumn{6}{|l|}{ Residence: } \\
\hline - Urban & 3 & 6 & 5 & 10 & 0.543 \\
\hline - Rural & 47 & 94 & 45 & 90 & 0.461 \\
\hline \multicolumn{6}{|l|}{ Occupation: } \\
\hline - Farmer & 13 & 26 & 8 & 16 & \\
\hline - Worker & 0 & 0 & 4 & 8 & 5.402 \\
\hline - Employer & 13 & 26 & 13 & 26 & 0.249 \\
\hline - Retired & 5 & 10 & 4 & 8 & \\
\hline - Housewife & 19 & 38 & 21 & 42 & \\
\hline \multicolumn{6}{|l|}{ Smoking: } \\
\hline - Yes & 15 & 30 & 8 & 16 & 2.767 \\
\hline - No & 35 & 70 & 42 & 84 & 0.096 \\
\hline \multicolumn{6}{|l|}{ Other health problems: } \\
\hline - None & 21 & 42 & 17 & 34 & \\
\hline - Hypertension & 21 & 42 & 22 & 44 & 8.778 \\
\hline - Respiratory & 0 & 0 & 7 & 14 & 0.032 \\
\hline - Others & 8 & 16 & 4 & 8 & \\
\hline \multirow{2}{*}{$\begin{array}{l}\text { Duration of heart disease / } \\
\text { years }(\overline{\mathbf{X}} \pm \mathrm{SD})\end{array}$} & \multirow{2}{*}{\multicolumn{2}{|c|}{$1.38 \pm 0.49$}} & \multirow{2}{*}{\multicolumn{2}{|c|}{$1.50 \pm 0.50$}} & $1.20 *$ \\
\hline & & & & & 0.231 \\
\hline \multicolumn{6}{|l|}{ Type of catheter: } \\
\hline - Diagnostic & 50 & 100 & 50 & 100 & ----- \\
\hline \multicolumn{6}{|l|}{$\begin{array}{l}\text { Times undergoing } \\
\text { catheterization: }\end{array}$} \\
\hline - First time & 50 & 100 & 50 & 100 & ----- \\
\hline
\end{tabular}

Table 2. Comparison between study and control group regarding knowledge of preparation of procedure at pre intervention $(n=100)$.

\begin{tabular}{llllll}
\hline Items & \multicolumn{3}{c}{ Study $(\mathbf{n}=\mathbf{5 0})$} & \multicolumn{3}{c}{ Control $(\mathbf{n}=\mathbf{5 0})$} & $\chi^{\mathbf{2}} \mathbf{P}$ \\
\cline { 2 - 5 } & No. & $\mathbf{\%}$ & No. & $\mathbf{\%}$ & value \\
\hline $\begin{array}{l}\text { Definition: } \\
\text { - Complete and correct }\end{array}$ & 7 & 14 & 13 & 26 & 2.435 \\
- Incomplete & 20 & 40 & 19 & 38 & 0.296 \\
- Incorrect or don't know & 23 & 46 & 18 & 36 & \\
Causes: & & & & & \\
- Complete and correct & 29 & 58 & 31 & 62 & 0.167 \\
- Incomplete & 0 & 0 & 0 & 0 & 0.683 \\
- Incorrect or don't know & 21 & 42 & 19 & 38 & \\
Insertion site: & & & & & \\
- Complete and correct & 8 & 16 & 8 & 16 & 1.248 \\
- Incomplete & 19 & 38 & 14 & 28 & 0.536 \\
- Incorrect or don't know & 23 & 46 & 28 & 56 & \\
Fasting period: & & & & & \\
- Complete and correct & 17 & 34 & 18 & 36 & 0.044 \\
- Incomplete & 0 & 0 & 0 & 0 & 0.834 \\
- Incorrect or don't know & 33 & 66 & 32 & 64 & \\
Medications: & & & & & \\
- Complete and correct & 18 & 36 & 13 & 26 & 2.277 \\
- Incomplete & 6 & 12 & 11 & 22 & 0.320 \\
- Incorrect or don't know & 26 & 52 & 26 & 52 & \\
Investigations: & & & & & \\
- Complete and correct & 5 & 10 & 6 & 12 & 0.102 \\
- Incomplete & 0 & 0 & 0 & 0 & 0.749 \\
- Incorrect or don't know & 45 & 90 & 44 & 88 & \\
$\begin{array}{l}\text { Anesthesia: } \\
\text { - Complete and correct }\end{array}$ & 3 & 6 & 8 & 16 & 2.554 \\
- Incomplete & 0 & 0 & 0 & 0 & 0.110 \\
- Incorrect or don't know & 47 & 94 & 42 & 84 & \\
Duration of procedure: & & & & & \\
- Complete and correct & 12 & 24 & 15 & 30 & 0.457 \\
- Incomplete & 0 & 0 & 0 & 0 & 0.499 \\
- Incorrect or don't know & 38 & 76 & 35 & 70 & \\
\hline & & & & & \\
\hline
\end{tabular}

Table 3. Comparison between study and control group regarding post procedural Knowledge at pre intervention $(n=100)$

\begin{tabular}{|c|c|c|c|c|c|}
\hline \multirow[b]{2}{*}{ Items } & \multicolumn{2}{|c|}{ Study $(n=50)$} & \multicolumn{2}{|c|}{ Control $(n=50)$} & \multirow{2}{*}{$\begin{array}{l}\chi^{2} \\
\text { P value }\end{array}$} \\
\hline & No. & $\%$ & No. & $\%$ & \\
\hline \multicolumn{6}{|l|}{ Position after procedure: } \\
\hline - Complete and correct & 5 & 10 & 3 & 6 & 0.550 \\
\hline - Incomplete & 14 & 28 & 15 & 30 & 0.759 \\
\hline - Incorrect or don't know & 31 & 62 & 32 & 64 & \\
\hline \multicolumn{6}{|l|}{ Leg fixation: } \\
\hline - Complete and correct & 13 & 26 & 7 & 14 & 3.189 \\
\hline - Incomplete & 5 & 10 & 3 & 6 & 0.203 \\
\hline - Incorrect or don't know & 32 & 64 & 40 & 80 & \\
\hline \multicolumn{6}{|l|}{ Frequency of vital signs: } \\
\hline - Complete and correct & 0 & 0 & 0 & 0 & 0.250 \\
\hline - Incomplete & 11 & 22 & 9 & 18 & 0.617 \\
\hline - Incorrect or don't know & 39 & 78 & 41 & 82 & \\
\hline \multicolumn{6}{|l|}{ Eating after procedure: } \\
\hline - Complete and correct & 5 & 10 & 4 & 8 & 3.157 \\
\hline - Incomplete & 0 & 0 & 3 & 6 & 0.206 \\
\hline $\begin{array}{l}\text { - Incorrect or don't know } \\
\text { Toileting: }\end{array}$ & 45 & 90 & 43 & 86 & \\
\hline - Complete and correct & 0 & 0 & 0 & 0 & ----- \\
\hline - Incomplete & 0 & 0 & 0 & 0 & ----- \\
\hline - Incorrect or don't know & 50 & 100 & 50 & 100 & \\
\hline \multicolumn{6}{|l|}{ Complications: } \\
\hline - Complete and correct & 0 & 0 & 0 & 0 & 3.787 \\
\hline - Incomplete & 20 & 40 & 11 & 22 & 0.052 \\
\hline - Incorrect or don't know & 30 & 60 & 39 & 78 & \\
\hline Symptoms of complications: & & & & & \\
\hline - Complete and correct & 0 & 0 & 0 & 0 & 1.099 \\
\hline
\end{tabular}




\begin{tabular}{|c|c|c|c|c|c|}
\hline \multirow{2}{*}{ Items } & \multicolumn{2}{|c|}{ Study $(n=50)$} & \multicolumn{2}{|c|}{ Control $(n=50)$} & \multirow{2}{*}{$\begin{array}{l}\chi^{2} \\
\text { P value }\end{array}$} \\
\hline & No. & $\%$ & No. & $\%$ & \\
\hline - Incomplete & 6 & 12 & 3 & 6 & 0.295 \\
\hline - Incorrect or don't know & & 88 & 47 & 94 & \\
\hline Total knowledge scores & 21.9 & \pm 4.08 & 21.8 & $0 \pm 4.67$ & $\begin{array}{l}0.114 \\
0.910\end{array}$ \\
\hline
\end{tabular}

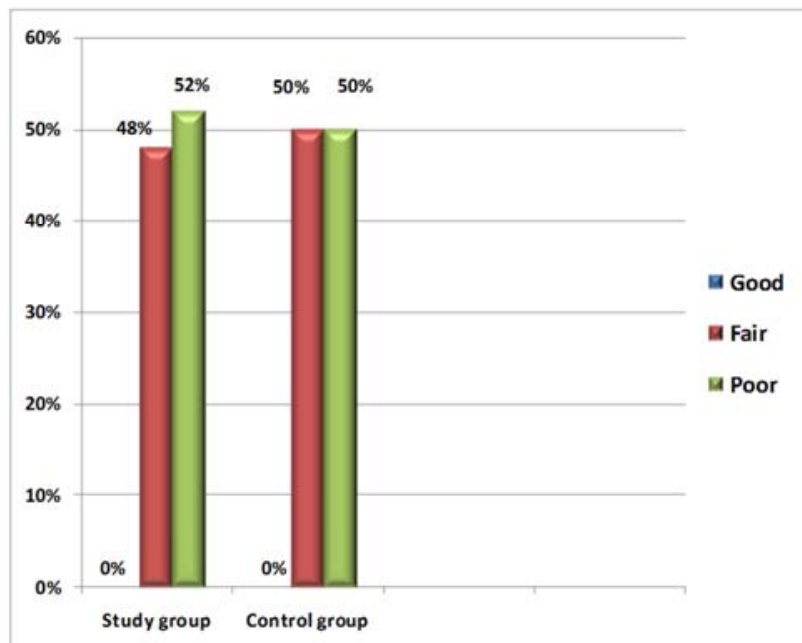

Figure 1. Total knowledge score among study and control groups at pre intervention $(n=100)$.

Table 4. Comparison between study and control group regarding knowledge of preparation of procedure at post intervention $(n=100)$.

\begin{tabular}{|c|c|c|c|c|c|}
\hline \multirow{2}{*}{ Items } & \multicolumn{2}{|c|}{ Study $(n=50)$} & \multicolumn{2}{|c|}{ Control $(n=50)$} & \multirow{2}{*}{$\begin{array}{l}\chi^{2} P \\
\text { value }\end{array}$} \\
\hline & No. & $\%$ & No. & $\%$ & \\
\hline \multicolumn{6}{|l|}{ Definition: } \\
\hline - Complete and correct & 13 & 26 & 8 & 16 & 7.474 \\
\hline - Incomplete & 26 & 52 & 18 & 36 & 0.024 \\
\hline - Incorrect or don't know & 11 & 22 & 24 & 48 & \\
\hline \multicolumn{6}{|l|}{ Causes: } \\
\hline - Complete and correct & 35 & 70 & 23 & 46 & 6.983 \\
\hline - Incomplete & 5 & 10 & 5 & 10 & 0.030 \\
\hline $\begin{array}{l}\text { - Incorrect or don't know } \\
\text { Insertion site: }\end{array}$ & 10 & 20 & 22 & 44 & \\
\hline - Complete and correct & 15 & 30 & 8 & 16 & 9.396 \\
\hline - Incomplete & 22 & 44 & 14 & 28 & 0.009 \\
\hline - Incorrect or don't know & 13 & 26 & 28 & 56 & \\
\hline \multicolumn{6}{|l|}{ Fasting period: } \\
\hline - Complete and correct & 35 & 70 & 18 & 36 & 19.70 \\
\hline - Incomplete & 4 & 8 & 0 & 0 & 0.0001 \\
\hline - Incorrect or don't know & 11 & 22 & 32 & 64 & \\
\hline \multicolumn{6}{|l|}{ Medications: } \\
\hline - Complete and correct & 24 & 48 & 12 & 24 & 7.600 \\
\hline - Incomplete & 12 & 24 & 12 & 24 & 0.022 \\
\hline $\begin{array}{l}\text { - Incorrect or don't know } \\
\text { Investigations: }\end{array}$ & 14 & 28 & 26 & 52 & \\
\hline - Complete and correct & 18 & 36 & 7 & 14 & 31.10 \\
\hline - Incomplete & 15 & 30 & 0 & 0 & 0.0001 \\
\hline \multicolumn{6}{|l|}{ Anesthesia: } \\
\hline - Complete and correct & 15 & 30 & 7 & 14 & 20.97 \\
\hline - Incomplete & 12 & 24 & 0 & 0 & 0.0001 \\
\hline - Incorrect or don't know & 23 & 46 & 43 & 86 & \\
\hline \multicolumn{6}{|l|}{ Duration of procedure: } \\
\hline - Complete and correct & 30 & 60 & 15 & 30 & 14.23 \\
\hline - Incomplete & 3 & 6 & 0 & 0 & 0.001 \\
\hline - Incorrect or don't know & 17 & 34 & 35 & 70 & \\
\hline
\end{tabular}

Table 5. Comparison between study and control group regarding post procedural Knowledge at post intervention $(n=100)$

\begin{tabular}{|c|c|c|c|c|c|}
\hline \multirow[b]{2}{*}{ Items } & \multicolumn{2}{|c|}{ Study $(n=50)$} & \multicolumn{2}{|c|}{ Control $(n=50)$} & \multirow{2}{*}{$\begin{array}{l}\chi^{2} \\
\text { P value }\end{array}$} \\
\hline & No. & $\%$ & No. & $\%$ & \\
\hline \multicolumn{6}{|l|}{ Position after procedure: } \\
\hline - Complete and correct & 18 & 36 & 3 & 6 & 16.98 \\
\hline - Incomplete & 17 & 34 & 15 & 30 & 0.0001 \\
\hline - Incorrect or don't know & 15 & 30 & 32 & 64 & \\
\hline \multicolumn{6}{|l|}{ Leg fixation: } \\
\hline - Complete and correct & 27 & 54 & 8 & 16 & 23.31 \\
\hline - Incomplete & 9 & 18 & 4 & 8 & 0.0001 \\
\hline - Incorrect or don't know & 14 & 28 & 38 & 76 & \\
\hline \multicolumn{6}{|l|}{ Frequency of vital signs: } \\
\hline - Complete and correct & 19 & 38 & 0 & 0 & 30.01 \\
\hline - Incomplete & 14 & 28 & 9 & 18 & 0.0001 \\
\hline - Incorrect or don't know & 17 & 34 & 41 & 82 & \\
\hline \multicolumn{6}{|l|}{ Eating after the procedure: } \\
\hline - Complete and correct & 25 & 50 & 4 & 8 & 30.56 \\
\hline - Incomplete & 9 & 18 & 3 & 6 & 0.0001 \\
\hline - Incorrect or don't know & 16 & 32 & 43 & 86 & \\
\hline \multicolumn{6}{|l|}{ Toileting: } \\
\hline - Complete and correct & 23 & 46 & 2 & 4 & 36.16 \\
\hline - Incomplete & 7 & 14 & 0 & 0 & 0.0001 \\
\hline - Incorrect or don't know & 20 & 40 & 48 & 96 & \\
\hline \multicolumn{6}{|l|}{ Complications: } \\
\hline - Complete and correct & 17 & 34 & 0 & 0 & 46.04 \\
\hline - Incomplete & 27 & 54 & 12 & 24 & 0.0001 \\
\hline - Incorrect or don't know & 6 & 12 & 38 & 76 & \\
\hline \multicolumn{6}{|l|}{ Symptoms of complications: } \\
\hline - Complete and correct & 16 & 32 & 0 & 0 & 30.45 \\
\hline - Incomplete & 12 & 24 & 3 & 6 & 0.0001 \\
\hline - Incorrect or don't know & 22 & 44 & 47 & 94 & \\
\hline Total knowledge scores: & 31.88 & & 21.5 & & $\begin{array}{l}9.246 \\
0.0001\end{array}$ \\
\hline
\end{tabular}

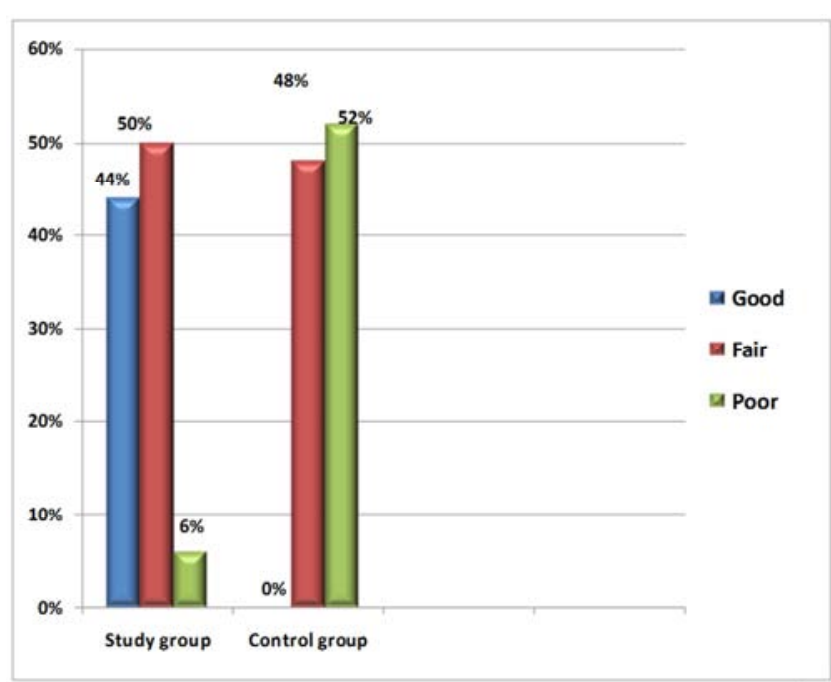

Figure 2. Total knowledge score among study and control groups at post intervention $(n=100)$ 
Table 6. Distribution of anxiety among both study and control group $(n=100)$.

\begin{tabular}{|c|c|c|c|c|c|}
\hline \multirow{2}{*}{ Items } & \multicolumn{2}{|c|}{ Study $(n=50)$} & \multicolumn{2}{|c|}{ Control $(n=50)$} & \multirow{2}{*}{$\begin{array}{l}\chi^{2} \\
\text { P value }\end{array}$} \\
\hline & No. & $\%$ & No. & $\%$ & \\
\hline \multicolumn{6}{|c|}{ Pre-procedure anxiety: } \\
\hline - None & 0 & 0 & 0 & 0 & \\
\hline - Mild & 7 & 14 & 3 & 6 & 6.561 \\
\hline - Moderate & 2 & 4 & 6 & 12 & 0.087 \\
\hline - Severe & 15 & 30 & 8 & 16 & \\
\hline - Extreme & 26 & 52 & 33 & 66 & \\
\hline $\mathrm{X} \pm \mathrm{SD}$ & \multicolumn{2}{|c|}{$30.70 \pm 8.29$} & \multicolumn{2}{|c|}{$32.24 \pm 7.20$} & $\begin{array}{l}0.991 \\
0.324\end{array}$ \\
\hline \multicolumn{6}{|c|}{ Anxiety at day of procedure: } \\
\hline - None & 0 & 0 & 0 & 0 & 38.49 \\
\hline - Mild & 26 & 52 & 7 & 14 & 0.0001 \\
\hline - Moderate & 15 & 30 & 9 & 18 & \\
\hline - Severe & 9 & 18 & 8 & 16 & \\
\hline - Extreme & 0 & 0 & 26 & 52 & \\
\hline $\mathrm{X} \pm \mathrm{SD}$ & \multicolumn{2}{|c|}{$17.18 \pm 6.37$} & \multicolumn{2}{|c|}{$31.16 \pm 11.89$} & $\begin{array}{l}7.324 \\
0.0001\end{array}$ \\
\hline \multicolumn{6}{|c|}{ Post procedure anxiety: } \\
\hline - None & 0 & 0 & 0 & 0 & 33.33 \\
\hline - Mild & 50 & 100 & 25 & 50 & 0.0001 \\
\hline - Moderate & 0 & 0 & 5 & 10 & \\
\hline - Severe & 0 & 0 & 10 & 20 & \\
\hline - Extreme & 0 & 0 & 10 & 20 & \\
\hline \multirow[t]{2}{*}{ - $\mathrm{X} \pm \mathrm{SD}$} & \multirow{2}{*}{\multicolumn{2}{|c|}{$4.48 \pm 2.25$}} & \multirow{2}{*}{\multicolumn{2}{|c|}{$17.12 \pm 11.98$}} & 7.330 \\
\hline & & & & & 0.0001 \\
\hline
\end{tabular}

Table 7. Mean scores of total anxiety among the studied subjects in relation to socio-demographic data $(n=100)$.

\begin{tabular}{|c|c|c|c|c|c|c|}
\hline \multirow{3}{*}{ Socio- demographic data } & \multicolumn{6}{|c|}{ Mean scores of Anxiety } \\
\hline & \multicolumn{2}{|c|}{ Pre procedure } & \multicolumn{2}{|c|}{ At day of procedure } & \multicolumn{2}{|c|}{ Post procedure } \\
\hline & $\mathbf{X} \pm \mathbf{S D}$ & $\begin{array}{l}\text { t- test } \\
\text { P value }\end{array}$ & $\mathbf{X} \pm$ SD & $\begin{array}{l}\text { - test } \\
P \text { value }\end{array}$ & $\mathbf{X} \pm \mathbf{S D}$ & $\begin{array}{l}\text { t- test } \\
\text { P value }\end{array}$ \\
\hline Age & $24.32 \pm 10.85$ & $\begin{array}{l}22.40 \\
0.0001\end{array}$ & $31.62 \pm 15.09$ & $\begin{array}{l}20.95 \\
0.0001\end{array}$ & $44.99 \pm 13.36$ & $\begin{array}{l}33.67 \\
0.0001\end{array}$ \\
\hline Gender & $29.92 \pm 7.61$ & $\begin{array}{l}39.28 \\
0.0001\end{array}$ & $22.62 \pm 11.74$ & $\begin{array}{l}19.26 \\
0.0001\end{array}$ & $9.25 \pm 10.64$ & $\begin{array}{l}8.687 \\
0.0001\end{array}$ \\
\hline Level education & $29.16 \pm 8.19$ & $\begin{array}{l}35.58 \\
0.0001\end{array}$ & $21.86 \pm 11.86$ & $\begin{array}{l}18.42 \\
0.0001\end{array}$ & $8.49 \pm 10.62$ & $\begin{array}{l}7.990 \\
0.0001\end{array}$ \\
\hline
\end{tabular}

*Significant $(\mathrm{P}<0.05)$

Table 8. Pearson correlation between knowledge and anxiety scores $(n=100)$.

\begin{tabular}{|c|c|c|c|c|c|c|}
\hline \multirow{3}{*}{ Knowledge } & \multicolumn{6}{|c|}{ Anxiety } \\
\hline & \multicolumn{2}{|c|}{ Pre procedure } & \multicolumn{2}{|c|}{ At day of procedure } & \multicolumn{2}{|c|}{ Post procedure } \\
\hline & $\mathbf{r}$ & $P$ value & $\mathbf{r}$ & P value & $\mathbf{R}$ & P value \\
\hline Pre intervention & 0.128 & 0.205 & - & - & - & - \\
\hline Post intervention & - & - & -0.228 & 0.022 & -0.288 & 0.004 \\
\hline
\end{tabular}

\section{Discussion}

Cardiac catheterization is a common interventional diagnostic procedure used in patients with acute coronary syndrome. Waiting for the procedure can be a major source of stress and anxiety. So patients should understand clearly information and given by the healthcare team due to decrease stress and anxiety.

Regarding to Sociodemographic characteristics the current study revealed that the mean age of the studied subjects were ranged from fifty five to fifty six years. Moreover, most them have primary education, lived in a rural area and suffered from hypertension. These events may affect knowledge and anxiety level among patients. These results were in agreement with Ali who assess the level of anxiety among patients scheduled for diagnostic cardiac catheterization. His results illusterated that finding which pointed on a high percentage of the sample were within primary education, married and housewives, also showed that the prevalence of cardiovascular risk factors was hypertension then smoking [25]. Allender et al., they stated that the mean age of participants was fifty five years [26].

However Harkness et al., they studied the effect of early education on patient anxiety while waiting for cardiac catheterization.. They found the mean age of outpatients in 
the larger study was sixty three years and sixty six percentage were males [27]. At same line Elsay et al., who study the effect of a multi-modal preparation package on knowledge and anxiety among patients undergoing cardiac catheterization. They found that the age distribution of the studied patient, fifty percentage were aged from fifty one to sixty years [28].

Regarding to patient's knowledge before and after intervention the present study showed that the almost half of study and control groups had poor knowledge before the intervention. However improve knowledge score among the study group than control group post intervention. These results may affect anxiety level and decreases anxiety among the study group. These results support by the study that carried by Garvin et al., that provided information about anxiety reduction with education intervention for patients undergoing cardiac catheterization. All subjects of their study reached the highest level of anxiety at the time just before cardiac catheterization and recorded the lowest at the time following the procedure. A lower level of anxiety was experienced by the experimental subjects who received the education intervention when compared with the control subjects who did not receive the education intervention before cardiac catheterization [29].

Moreover Abdollahzadeh et al., they studied the effect of video education on knowledge and satisfaction of patients undergoing coronary angiography. They noticed that the education has been significantly increasing patients' awareness and satisfaction [30]. Furthermore Harkness et al., reported that patients who received the early education intervention had a reduction in perceived anxiety [27]. Also Elsay et al., showed that the information provided to patients is very important aspect of care, lesser amount of information leading to greater anxiety, also they found, total knowledge score unsatisfied in all patient pre intervention compared to post intervention [28]. Buzatto and Zanei, added that the main factors that increase levels of anxiety before the procedure were lack of information and unsatisfactory orientation, and increase waiting time before the procedure. So early preparation, giving patients information before the procedure were very important to decrease levels of anxiety [13]. These findings supports the results of the our study, there were a correlation between the knowledge and anxiety.

Regarding to anxiety level (pre, at day of the procedure and post procedure) the current study showed that most of the study and the control groups have high anxiety that ranged from severe and extreme level of anxiety with no statistical significance differences in pre procedure period. On the other hand the anxiety level decreases among the study group compared to the control group during the day of the procedure and post procedure. These results supported by Nekouei et al., who compare Anxiety between cardiac patients and normal populations during catheterization. They found that most cardiac patients as cardiac catheterization suggested that patient' anxiety increases before and during the procedure and causes symptoms including irritability, restlessness, insomnia, busy mind, anorexia and hyperphagia.
In addition found that in spite of good results of angiography and the certainty of the cardiologist, patients leave the hospital with anxiety [11]. Furthermore Buzatto and Zanei reported that anxiety is a common emotion before cardiac catheterization [13].

Moradi and Hajbaghery, who assessed state of anxiety in patients undergoing coronary angiography found that the anxiety of patients before invasive procedures reported a relatively high level of anxiety. Besides the results showed that the educational program for patients awaiting angiography reduced anxiety before and after angiography compared to the control group [31]. In addition Elsay et al., who evaluate the effect of a multi modal preparation package on anxiety in patients undergoing coronary angiography. They found that anxiety were the same among study and control group before and on the day of procedure, but decreased among the study group than control group during the procedure [28].

At the same line Jamshidi et al., reported a significant decrease in the patients' anxiety after presenting the training videos and most of patients waiting for angiography reportedly lack adequate information about this medical procedure, making them anxious [17]. Mohammadi et al., indicated that both individuals and groups training significantly reduced anxiety in patients undergoing cardiac catheterization [9]. Yeganeh Khah et al., added that patient education through face to face training and using pamphlets or CDs could reduce the anxiety level in patients with myocardial infarction [32]. The results of the current study were also consistent with Guo et al., who concluded hat answering patients' questions, giving detailed information about the intended procedure, and environmental orientation of patients could reduce patients' anxiety and uncertainties before different surgeries and invasive procedures [33].

The present study showed that there were relationship between age, gender and level of education. So anxiety level among the studied subjects could be affected by sociodemographic data. Highly statistically significant differences and correlations were found between anxiety level and age, gender and level of education. These results supported by Moradi and Hajbaghery who stated that there were a significant difference existed between the male and female patients regarding anxiety [31]. Yeganeh khah et al., they found a higher level of anxiety in females compared with males among the hospitalized patients with myocardial infarction. It may be speculated that the higher level of anxiety in female patients may stem from the fact that women experience coronary artery disease at an older age as compared with male patients, and experience more severe limitations after that thus they have lower resistance against stresses [32]. Furthermore, Ali and Bjelland were found significant relation between anxiety and gender, the female had high level of anxiety than male, because women expressed greater anxiety than the men. Also there were significant relation between anxiety and gender [25, 34].

The results of a current study cleared that no significant difference was found between the age groups in relation to 
anxiety. Nevertheless, previous studies did not identify any significant difference in the anxiety level in different age group. Moreover, there were significant relation between anxiety and education, patients with low education level have high levels of anxiety. At the same line Uzun et al., they showed that patient education would reduce their anxiety, increase their adaptability before surgery and could decrease the length of their hospital stay [22].

\section{Conclusion}

Based on the findings of the presented study, it can be concluded that, the early preparation and gave patients' information before cardiac catheterization improve patients' knowledge, increase information about pre and post operative care of the procedure so all of these measures helpe in reducing the patients' anxiety level.

\section{Recommendations}

- A qualified nurses should take the responsibility to determine the information preparation of patient's to cardiac catheterization.

- Establishment of an educational teaching booklet about cardiac catheterization because it can teach a large number of patients in a short period of time.

- Further studies involving studies a large number of patients can be conducted to detect that the health education can influence the patient overall adaptation.

\section{References}

[1] Alizadehsani R, Habibi J, Hosseini MJ, Mashayekhi H, Boghrati R, Ghandeharioun A, \& et al., (2013). A data mining approach for diagnosis of coronary artery disease. Comput Methods Programs Biomed., 111(1):52-61.

[2] WHO Cardiovascular disease. World Health Organization; (2013). [Cited accessed August 28, Available from: http://www.who. int/cardiovasculardiseases/en/index.html.

[3] Lavi S., Kandzari D., Barsness G. In: Barsness I, Holmes D, (2012). Coronary Artery Disease. London: Springer;

[4] Wilcoxson VL.,.( 2012). Early Ambulation After Diagnostic Cardiac Catheterization via Femoral ArteryAccess. J Nurse Pract., 8 (10):810-5.

[5] Mikosch P., Hadrawa T., Laubreiter K., Brandl J., Pilz J, Stettner H., \& et al., (2010). Effectiveness of respiratorysinus-arrhythmia biofeedback on state-anxiety in patients undergoing coronary angiography. J Adv Nurs., 66(5):110110 .

[6] McEnroe-Petitte, Denise M. MSN, RN, (2015). Influence of Music on Preoperative Anxiety and Physiologic Parameters in Women Undergoing Gynecologic Surgery November, Volume :41 Number 11 - P., 14-15.

[7] Dogan MV, Senturan L. (2012). The effect of music therapy on the level of anxiety in the patients undergoing coronary angiography. Open J Nurs. ;02(03):165-9.
[8] Weeks BP, \& Nilsson U. (2011). Music interventions in patients during coronary angiographic procedures: a randomized controlled study of the effect on patients' anxiety and well-being. Eur J Cardiovasc Nurs., 10(2):88-93.

[9] Mohammadi N., Tizhoosh M., Seyedoshohadaei M.,\& Haghani H. (2012). Face-to-Face Education vs. Group Education on Knowledge and Anxiety of Patients Undergoing Coronary Angiography [in Persian]. Hayat. 18(3):44-53.

[10] Mahmoudirad G, Ghaedi Mosolo M, \& Bahrami H. (2014). Effect of foot reflexology on anxiety of patients undergoing coronary angiography. Iran J Crit Care Nurs., 6(4):235-42.

[11] Nekouei ZK, Yousefy A, Manshaee G, \& Nikneshan S.( 2011). Comparing anxiety in cardiac patients candidate for angiography with normal population. ARYA Atheroscler, 7(3):93-6

[12] Dogan MV,\& Senturan L. (2012). The effect of music therapy on the level of anxiety in the patients undergoing coronary angiography. Open J Nurs., 02(03):165-9.

[13] Buzatto LL, Zanei SS. (2010). Patients' anxiety before cardiac catheterization. Einstein (Sao Paulo), 8(4):483-7.

[14] University of Iowa Department of Internal Medicine, (2008). Cardiac Catheterization. URL available at: http://www.uihealthcare.com

[15] Buffum MD, Sasso C., Sands LP, Lanier E, Yellen M., \& Hayes A.(2006). A music intervention to reduce anxiety before vascular angiography procedures. J Vasc Nurs., 24(3):68-73.

[16] Brunner LS, Suddarth DS, O'Connell Smeltzer SC. (2004). textbook of medical-surgical nursing.Philadelphia: Lippincott Williams \& Wilkins.

[17] Jamshidi N., Abbaszadeh A., Najafi Kaliani M., (2010). The effects of video education on comfort and tolerability of patients undergoing coronary angiography. Iranian Journal of Nursing Research, 5(16):38-44.

[18] Seyam S, Hidarnia A, \& Tavafian S. (2011). Self-care Education through Coping Style for Patients after Heart Surgery. Journal of Isfahan Medical School, 29(135).

[19] Mousavi S., Sabzevari S., Abbaszade A., \& Hosseinnakhaie F., (2011).The effect of preparatory face to face education to reduce depression and anxiety in open heart surgery adult patient in Shafa hospital in Kerman, 2008. Iranian Journal of Nursing Research.

[20] Jamshidi N., Abaszade A.,\& Najafi-Kaliani M., (2012). Stress, anxiety and depression of patients before coronary angiography. Zahedan Journal of Research in Medical Sciences, 13(10):29.

[21] Gallagher R, Trotter R, Donoghue J. (2010). Pre procedural concerns and anxiety assessment in patients undergoing coronary angiography and percutaneous coronary interventions. European Journal of Cardiovascular Nursing, 9(1):38-44.

[22] Uzun S, Vural H, Uzun M., \& Yokusoglu M. (2008).State and trait anxiety levels before coronary angiography. Journal of clinical nursing; 17(5):602-7.

[23] Dakheel, F. I.; Smko, R. \& Negrat, K. (2011). Using Data Mining Techniques for Finding Cardiac Outlier Patients. Engineering and Technology, Vol. 73, pp. 442-447. 
[24] Hamilton, M., (1959). The assessment of anxiety states by rating. BrJMed Psychol. 32:50-55.

[25] Ali, s., (2015). Determination the level of anxiety among patients scheduled for diagnostic cardiac catheterization. Journal of Babylon University/Pure and Applied Sciences/ No.(2)/ Vol. (23).

[26] Allender S, Scarborough P., Peto V et al., (2008). European Cardiovascular Disease Statistics. http://tinyurl.com/dkba24

[27] Harkness K., Morrow L., Smith K., Kiczula M., \& Arthur H., (2003).The effect of early education on patient anxiety while waiting for elective cardiac catheterization. Eur J Cardiovasc Nurs., 2(2):113-21. 41.

[28] Elsay, O., Elshemy, M., \& HalaElsays, (2016). Effect of a Multi-Modal Preparation Package on knowledge and anxiety among Patients Undergoing cardiac Catheterization. International Journal of Nursing Didactics, $6: 01$ January.

[29] Garvin, (2003). Effects of Gender and Preference for Information and Control on Anxiety Early after Myocardial Infarction, Nursing Research, Vol. 52 - Issue 6, pp: 386-392
[30] Abdollahzadeh, F.,, Moghaddasian, S., Rahmani,A.,\& Shahmari, M., (2014). Effect of video education on knowledge and satisfaction of patients undergoing coronary angiography * Iran J Crit Care Nurs. 7(3): 168-175.

[31] Moradi, T., \&, Hajbaghery, M., (2015). State and Trait Anxiety in Patients Undergoing Coronary Angiography International Journal of Hospital Research,4(3): 123-128.

[32] Yeganeh,A., Akbari, H.,\& Ziyayi M.,. (2012). Comparison of Different Methods of Education on Reducing the Anxiety of Patients with Myocardial Infarction. Iran Journal of Nursing, 24(74):36-44.

[33] Guo P, East L.,\& Arthur A., (2012). A preoperative education intervention to reduce anxiety and improve recovery among Chinese cardiac patients: a randomized controlled trial. Int J Nurs Stud. 49(2):129-37.

[34] Bjelland I., Krokstad S., Mykletun A., Dahl A.,Tell G. and Tambs k., (2008), Does a higher educational level protect against anxiety and depression. The HUNT study, Social Science \& Medicine, Volume 66, Issue 6, pp: 1334-1345. 